\title{
Da abordagem de sistemas abertos à complexidade: algumas reflexões sobre seus limites para compreender processos de interação social
}

\author{
Maria Ceci A. Misoczky*
}

\section{Resumo}

Este ensaio inicia com considerações sobre o papel de metáforas e modelos na construção e disseminação de teorias. Posteriormente, revisa as abordagens que compõem o pensamento sistêmico - sistemas abertos, cibernética, autopoiese e complexidade - sendo que cada uma delas é criticada a partir da referência ao modo pelo qual contemplam (ou não) a interação social e a possibilidade da mudança. Nas considerações finais retoma-se 0 tema das metáforas e modelos para discutir alguns riscos da transposição simplista de conhecimento entre campos disciplinares.

Palavras-chave : Teoria de sistemas, teoria da complexidade, auto-organização, mudança.

\begin{abstract}
This essay begins with some considerations on the role played by metaphors and models in the construction and dissemination of theories. Following, there is a review of the main systemic thought approaches - opens systems, cybernetics, autopoiesis and complexity. Each one is criticized having as reference the way they consider (or do not consider) social interaction and possibility of change. In the final considerations metaphors and models are considered again, in order to discuss some risks of simplistic transposition of knowledge between disciplinary fields.
\end{abstract}

Palavras-chave : System theory, complexity theory, self organization, change.

$\mathrm{Na}$ atualidade, a expressão teoria sistêmica desperta uma grande variedade de significados, inclusive entre aqueles que a adotam como referência. Segundo Rodrigues Jr (2000) isso se deve ao fato de que sua emergência aconteceu de forma interdisciplinar (biologia, cibernética, física, química, economia, ciências sociais), com as diferentes disciplinas formulando "teorias sistêmicas" próprias e adaptando os conceitos-chave a um novo elenco conceitual. Além disso ocorre, nas últimas décadas, o desenvolvimento de um "novo pensamento sistêmico", denominado teoria da auto-organização ou, ainda, teoria da complexidade.

Thrift (1999) considera a teoria da complexidade como um amálgama científico, um híbrido retórico; afirmando, ainda, que a razão principal para sua popularidade reside no seu caráter anti-reducionista. Seria, segundo Ingold (1990), uma ciência que afirma a primazia de processos sobre eventos, de relações sobre entidades, do desenvolvimento sobre a estrutura. Algumas expressões são características dessa abordagem, tais como não-linearidade, auto-organização, ordem emergente, sistemas adaptativos complexos, posição do observador.

Assim como a teoria de sistemas abertos, a teoria da complexidade se baseia em um "conjunto de metáforas que se referem à ordem holística emergente", capazes de viajar e de se tornarem, gradualmente, um senso comum (THRIFT, 1999, p.35). Adotar essa perspectiva leva a uma reflexão inicial sobre o significado do uso de metáforas e sobre as implicações de tomá-las como verdade, esquecendo-se que são, apenas e simplesmente, metáforas. Essa reflexão se encontra no primeiro item desse ensaio. A seguir, é feita uma breve revisão da teoria de sistemas à teoria da complexidade, seguida de críticas feitas a partir de diferentes posicionamentos, tendo como referência o modo pelo qual essas abordagens contemplam a interação social e a possibilidade de mudança.

* Doutora em administração, mestre em planejamento urbano regional, docente da Escola de Administração/PPGA/UFRGS. E-mail: mcamisoczky@ ea.ufrgs.br. 


\section{Sobre metáforas e modelos}

Goodman (1968, p.69) define metáfora como a aplicação de uma etiqueta familiar - cujo uso tem um passado a um objeto novo que, primeiramente, resiste, mas depois cede. "Aplicar uma velha etiqueta de modo novo é ensinar novos caminhos para uma velha palavra. A metáfora é um idílio entre um predicado que tem um passado e um objeto que tudo cede, protestanto." Aqui, a metáfora está vinculada à referência, à transferência de relações, de predicados, de um objeto para outro(s). Ricoeur (2000, p.360) utiliza o exemplo de "falar sobre a sonoridade de uma pintura", que "não é fazer emigrar um predicado isolado, mas assegurar a incursão de todo um reino sobre um território estrangeiro; o famoso 'transporte' torna-se uma migração conceitual, tal como uma expedição além-mar com armas e bagagens". O interessante é que "a organização efetuada no reino estrangeiro é guiada pelo emprego da rede inteira do reino de origem; isso significa que a escolha do território de invasão é arbitrária (...), o uso de etiquetas no novo campo de aplicação é regulado pela prática anterior."

Criticando essa perspectiva nominalista, segundo a qual a regra do emprego de etiquetas é a regra do precedente (GOODMAN, 1968), Ricoeur (2000) pergunta se faz sentido procurar a diferença entre o literal e o metafórico (uma pessoa e um quadro se assemelham quando estão tristes?). As formulações de Black (1962, p.37) ajudam a responder essa questão. Segundo esse autor "a metáfora cria a semelhança, mais que a encontra ou a exprime".

Black (1962) relaciona metáforas e modelos, argumentando que a metáfora é para a linguagem poética o que o modelo é para a linguagem científica, quanto à relação com o real. Lembrando que o modelo corresponde à lógica da descoberta (não à lógica da prova), Black (1962) o define como uma rede complexa de enunciados, como uma rede metafórica (e não uma metáfora isolada). Seu correspondente seria, então, o da metáfora continuada - a fábula, a alegoria. Segundo Ricoeur (2000) um dos benefícios dessa passagem pela noção de modelo reside em que ela destaca a conexão entre função heurística e descrição. Assim, aos modelos corresponde descrever um domínio menos conhecido - a realidade - em função de relações com um domínio fictício melhor conhecido. A mimesis passa a ser comprendida não mais em termos de cópia, mas de redescrição. Ou melhor, de "redescrição lírica", na medida em que incorpora o elemento fictício na teoria do modelo, em que se alia ficção e redescrição na experiência da realidade, em que inventar e descobrir deixam de se opor e na qual criar e revelar são coincidentes. A metáfora se torna, nesse sentido, uma "estratégia de discurso pela qual a linguagem se despoja de sua função de descrição direta para aceder ao nível mítico no qual sua função de descoberta é liberada" (RICOEUR, 2000, p.376).

Permanece, ainda, o tema da "verdade metafórica", a pergunta sobre o que significa a realidade. Ricoeur (2000, p.378 e 388) busca resolver essa questão através da teoria da tensão: entre conteúdo e veículo; entre interpretação literal e impertinência metafórica que faz sentido com o não-sentido; entre identidade e diferença no jogo da semelhança. "A tensão seria entre um 'é' e um 'não é'. (...) enfatiza o caráter paradoxal incontornável que se vincula a um conceito metafórico de verdade. O paradoxo consiste em que não há outro modo de fazer justiça à noção de verdade metafórica, senão incluindo o aguilhão crítico do 'não é'." Trata-se de confirmar a linguagem metafórica, acrescentado-lhe o índice crítico do 'como se'.

Uma outra abordagem "preocupada" com o uso de metáforas de modo não-reflexivo se encontra em Bourdieu, Chamboredon e Passeron (1999, p.34). Em seu alerta sobre a necessidade de "controlar as significações flutuantes de todas as metáforas", os autores expressam a crítica à transposição automática de imagens originárias da natureza física ou biológica para outros campos de conhecimento.

"(...) metáforas que ameaçam situar a coerência de seu discurso em uma natureza diferente daquele em que ele pretende inscrever suas formulações. Ou seja, algumas dessas imagens que poderiam ser classificadas segundo a natureza, biológica ou mecânica, à qual elas reenviam, ou segundo as filosofias implícitas do social que elas sugerem: equilíbrio, pressão, força, tensão, reflexo, raiz, corpo, célula, secreção, crescimento, regulação, gestação, enfraquecimento, etc. Tais esquemas de interpretação, tirados quase sempre da natureza física ou biológica, ameaçam veicular, sobre a aparência da metáfora e da homonímia, uma filosofia inadequada da vida social e, sobretudo, desencorajar a busca da explicação específica, fornecendo sem grandes esforços uma aparência de explicação." 
Na defesa da realização do "corte epistemológico" pelas ciências sociais, os autores afirmam a importância da utilização social dos esquemas de interpretação do social, aceitando a utilização eventual de esquemas analógicos a partir da física moderna, com a condição de utilizá-los de forma consciente e metódica.

Nesse sentido é interessante recorrer a Canguilhem $(1977,1999)$ que, em seus estudos sobre as relações entre epistemologia e história das ciências, mostra como o conceito de estrutura orgânica, desenvolvido por Claude Bernard no nascimento da patologia, a partir da embriologia e da citologia experimentais, estava "associado de forma muito estreita ao modelo social que, no final de contas, não passava, talvez, de uma metáfora". Ou seja, Barnard constrói a metáfora tendo como referência uma sociedade de tipo liberal - porque é a sociedade de seu tempo que ele toma como modelo - na qual as condições de vida individual são respeitadas e poderiam ser prolongadas fora da associação, sob reserva de se beneficiarem, artificialmente, de um meio apropriado. Refletindo sobre essas transposições entre campos de conhecimento e sobre a perda do aguilhão crítico do 'não é', Canguilhem (1999, p.169) alerta para a necessidade de se manter em mente que "para o organismo, a organização é um fato; enquanto para a sociedade é uma questão".

\section{Da teoria de sistemas à teoria da complexidade}

\section{Sistemas abertos}

A teoria geral de sistemas se desenvolve a partir das formulações do biólogo L. Von Bertalanffy que, em 1940, afirma ser necessário tratar os problemas que cercam os seres humanos como "típicos de sistemas", considerando seus contornos, seus componentes e as relações entre as partes. Esse autor lança o desafio da construção de uma disciplina que tivesse como objetivos principais investigar isomorfismos de conceitos, leis e modelos em campos diferentes; e ajudar nas transferências úteis entre os campos, promovendo a unidade das ciências.

Portanto, os princípios da teoria geral de sistemas reproduzem idéias previamente desenvolvidas para entender sistemas biológicos e incluem (MORGAN, 1996):

- homeostase - auto-regulação para manter um estado estável; sendo obtida através de processos que relacionam e controlam a operação sistêmica pelo mecanismo da retroalimentação (desvios de algum padrão ou norma desencadeiam ações de correção);

- entropia/entropia negativa - sistemas fechados tenderiam ao desaparecimento pela entropia; sistemas abertos buscam a auto-sustentação, importando energia do ambiente para atingir condições de estabilidade;

- estrutura, função, diferenciação e integração - estando intrinsecamente inter-relacionados permitem a autosustentação;

- requisito da variedade - relacionada com a idéia de diferenciação e integração, afirma que os mecanismos regulatórios internos precisam ser tão diversificados quanto a diversidade do ambiente com o qual se relacionam;

- eqüifinalidade - em um sistema aberto podem existir muitos modos diferentes de chegar a um dado estado final, ou seja, a estrutura do sistema em um dado momento não é mais que um aspecto ou manifestação de um processo funcional mais complexo (ela não determina o processo);

- evolução do sistema - capacidade que depende da habilidade de mover-se para formas mais complexas de diferenciação e integração, e para maior variedade, facilitando a habilidade de lidar com desafios e oportunidades colocadas pelo ambiente (envolve processos cíclicos de variação, seleção e retenção de características selecionadas).

A concepção de sistema aberto, desenvolvida por Von Bertalanffy a partir do estudo de sistemas vivos, resolve o problema do pensamento sistêmico em sua relação com a segunda lei da termodinâmica - o da tendência à entropia inerente a todo sistema fechado -, ao estabelecer as trocas de matéria e energia com o meio como forma de manter o estado de ordem. 
Um outro aspecto dessa abordagem envolve a concepção do sistema contendo o todo dentro do todo. Assim, sistemas contêm subsistemas que, por sua vez, podem ser sistemas abertos e que, portanto, interagem entre si, com o sistema ao qual pertencem e com o ambiente.

Segundo Katz e Khan (1975) a abordagem de sistema aberto mais desenvolvida é a de Parsons (1973a, 1973b), no seu estudo das estruturas sociais.

"Todos os sistemas sociais, inclusive as organizações, consistem em atividades padronizadas de uma quantidade de indivíduos. (...) essas atividades são claramente complementares ou interdependentes em relação a algum produto ou resultado comum; elas são repetidas, duradouras e ligadas em espaço e tempo. A estabilidade ou recorrência de atividades pode ser examinada em relação ao insumo de energia no sistema, à transformação de energia dentro do sistema, e ao produto resultante ou produção de energia. Um aspecto importante é que a teoria de sistemas está interessada pelos problemas de relações de estrutura e de interdependência, e não pelos atributos constantes dos objetos" (KATZ e KHAN, 1975, p.32-33).

Daí resulta uma visão das estruturas sociais como sistemas de natureza planejada, que representam padrões de relacionamento. Esses padrões conduziriam a uma grande variabilidade, não fosse a existência de forças que a reduzem: pressões do ambiente, valores e expectativas compartilhadas, imposição de regras - "em todos os sistemas sociais a variabilidade do comportamento social é posta sob controle por um ou mais desses dispositivos" (KATZ e KHAN, 1975, p.53). Sendo assim, os membros de sistemas sociais desempenham um papel, seu comportamento é prescrito e sancionado por normas, as quais estão enraizadas em valores. Desses componentes, por sua vez, derivam as bases da integração: interdependência funcional de papéis, coesão através de requisitos normativos e valores centralizados nos objetivos do sistema.

\section{Figura 1}

Características de sistemas sociais (a partir de Katz e Kahn, 1975) e Parsons (1968)

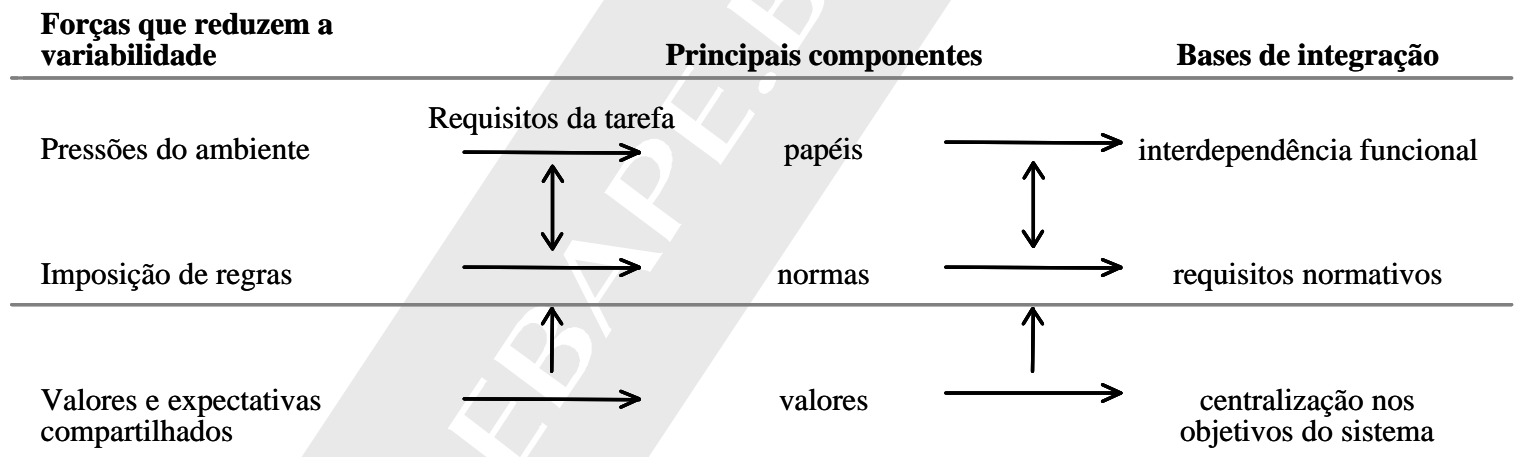

No que se refere à mudança em sistemas sociais, Parsons (1968, p.84) a define como um processo de crescimento, que pode implicar tanto em "aumento quantitativo da magnitude do sistema", quanto em "mudança qualitativa" ou "diferenciação estrutural e desenvolvimento simultâneo de modelos e mecanismos que integram ou unificam as partes diferenciadas". Dessa concepção de mudança decorre que qualquer sistema pode ser descrito, por um lado, "como uma estrutura e um conjunto de unidades ou componentes que (...) têm propriedades estáveis" e, por outro, "como acontecimentos ou processos no curso dos quais 'acontece algo' que muda algumas propriedades e algumas relações entre elas". Em outras palavras, processos de mudanças são processos que transformam o estado inicial de equilíbrio e, depois, estabelecem um novo estado de equilíbrio.

Os já mencionados limites à variabilidade permitem a estabilidade do sistema, mesmo em processos de mudança. "O conceito de equilíbrio estável supõe que, mediante mecanismos integradores, se mantém as variações endógenas dentro de limites compatíveis com a conservação dos principais tipos estruturais e que, mediante mecanismos adaptativos, também se mantém dentro de certos limites as flutuações entre o sistema e o ambiente" (PARSONS, 1968, p.88). 


\section{Cibernética}

A essa aproximação entre física e biologia segue-se a produção do campo da cibernética, com o desenvolvimento da noção de retroalimentação negativa. Nesse mesmo campo emerge o problema da autoorganização, a partir da teoria dos autômatos auto-reprodutores e de uma tentativa de teoria metacibertnética. A definição de auto-organização parte da idéia de que novas estruturas podem emergir da própria dinâmica dos elementos que as constituem, em determinados domínios e circunstâncias (DEBRUN, 1996).

Ciberneticistas como Von Neuman, Winograd, Cowan e Ashby buscavam os princípios de construção de autômatos cuja confiabilidade fosse maior que a de seus componentes, o que resultou em uma série de compromissos entre determinismo e indeterminismo, como se uma certa quantidade de indeterminação fosse necessária, a partir de um certo nível de complexidade, para permitir que o sistema se adaptasse a certo nível de ruído (ALEKSANDROWICZ, 2002). Morin (1995) aponta dificuldades para avanços da cibernética nessa direção, dadas as limitações da teoria e da tecnologia naquele momento. No entanto, registra a importância de suas posições de partida:

- Schrödinger destaca, desde 1945, o paradoxo da organização viva, a qual não parece obedecer ao segundo princípio da termodinâmica;

- Von Neumann inscreve o paradoxo na diferença entre a máquina viva (auto-organizadora) e a máquina artefato (simplesmente organizada), mostrando que existe um elo entre desorganização e organização complexa - o fenômeno da desorganização (entropia) prossegue seu curso no ser vivo de modo inseparável do fenômeno da reorganização (neguentropia).

Ainda segundo Morin (1995), a idéia da auto-organização opera uma grande mudança no estatuto ontológico do objeto, que vai além da ontologia cibernética.

"Ao mesmo tempo em que o sistema auto-organizador se destaca do meio e se distingue dele, pela sua autonomia e individualidade, liga-se tanto mais a ele pelo crescimento da abertura e da troca que acompanham qualquer processo de complexidade: ele é auto-eco-organizador. Enquanto o sistema fechado tem pouca individualidade, não tem trocas com o exterior e está em muito pobres relações com o meio, o sistema auto-eco-organizador tem a sua individualidade, ela mesma ligada a relações muito ricas e, portanto, dependentes do meio. Mais autônomo, está menos isolado. Tem necessidade de alimentos, de matéria/energia, mas também de informação, de ordem. O meio está por isso mesmo no seu interior, e desempenha um papel co-organizador. O sistema auto-eco-organizador não pode, portanto, bastar-se a ele próprio, só pode ser totalmente lógico ao introduzir, nele, o meio estranho Ele não pode terminar-se, fechar-se, autobastar-se" (MORIN, 1995, p.49).

Os quatro princípios-chave da cibernética estão relacionados a uma teoria de comunicação e aprendizagem. Os sistemas precisam ter capacidade para perceber, monitorar, decompor aspectos significativos do seu ambiente; de relacionar essas informações às normas operantes que guiam o comportamento de sistemas; de detectar desvios significativos dessas normas; de iniciar ações corretivas quando discrepâncias são detectadas. "Deste modo o sistema pode operar de um modo inteligente e auto-regulante. Entretanto, as habilidades de aprendizagem assim definidas são limitadas de modo que o sistema pode manter somente o curso de ação determinado pelas normas operantes ou pelos padrões que as guiam." Essas limitações levaram ao desenvolvimento, na cibernética, da distinção entre o processo de aprendizagem e o processo de aprendizagem para aprender. Nessas situações, sistemas cibernéticos complexos - como o cérebro humano ou computadores avançados - podem detectar ou corrigir erros nas normas operantes e, assim, influenciar os padrões que guiam suas operações (MORGAN, 1996, p.86).

Uma das influências mais relevantes na administração é a desenvolvida por Beer (1979), que destaca a contribuição da cibernética para o controle nas organizações. Outra influência, mais recente, se encontra na abordagem da aprendizagem organizacional, desenvolvida por Argyris e Shöen, popularizada por Peter Senge.

A forma como o tema da mudança é tratado, na análise cibernética, fica claro no texto de Cadwaller (1968, p.149-150). 
"O tema fundamental da cibernética é sempre a regulação e o controle de sistemas abertos. Interessa a homeostase nos organismos e os estados permanentes nas organizações sociais. (...) Alguns tipos de estabilidade negam certos tipos de mudança. $\mathrm{O}$ que se esquece é que pelo menos uma categoria de estabilidade depende da mudança e é conseqüência dela. Precisamente esse tipo de estabilidade tem interesse primordial para a cibernética. Um sistema aberto, seja social ou biológico, em um ambiente que muda, ou muda ou perece. Nesse caso, o único caminho para sobreviver é mudar. A capacidade de persistir mediante uma mudança de estrutura e na conduta recebeu o nome de 'ultra-estabilidade'. Outra maneira de expressar o anterior consiste em dizer que alguns sistemas abertos se adaptam a um ambiente flutuante mediante processos de aprendizagem e inovação."

\section{Autopoiese}

Os estudos em torno do conceito de auto-organização continuam a se desenvolver entre os ciberneticistas, mas a contribuição mais importante para sua sistematização viria da biologia, ainda que sob a influência da cibernética. Maturana e Varela (1986) adotam a perspectiva do observador, formulando uma teoria para a compreensão cibernética do observador de sistemas. Surge o observador do observador, a cibernética de segunda ordem, e o observador de sistemas sociais, a cibernética de terceira ordem. Autopoiese, nessa concepção, se refere à constante autoprodução dos seres vivos e inclui a diferenciação entre organização e estrutura. Organização é o conjunto de relações que ocorrem entre os componentes; a estrutura compreende os componentes e relações que constituem uma unidade particular, realizando sua organização. Os sistemas vivos são, nessa concepção, organizações fechadas, sistemas autônomos de interação que fazem referência somente a si mesmo. A idéia de que sistemas biológicos são abertos ao ambiente é apenas o resultado de um esforço, do observador, para dar sentido a esses sistemas do seu ponto de vista - de observador externo (MATURANA e VARELA, 1979). A base dessa argumentação é que os sistemas vivos possuem três características principais: autonomia, circularidade e auto-referência.

"Um ser vivo ocorre e consiste na dinâmica de realização de uma rede de transformações e de
produções moleculares, tal que todas as moléculas produzidas e transformadas no operar dessa rede
formam parte da rede, de modo que, com as suas interações: a) geram a rede de produções e de
transformações que as produziu e as transformou; b) dão origem às fronteiras e à extensão da rede
como parte do seu operar como rede, de modo que esta fica dinamicamente fechada sobre si mesma,
formando um ente molecular discreto que surge separado do meio molecular que o contém por seu
próprio operar molecular; c) configuram um fluxo de moléculas que, ao incorporar-se na dinâmica da
rede, são partes ou componentes dela, e ao deixar de participar da dinâmica da rede deixam de ser
componentes e passam a ser parte do meio" (MATURANA e VARELA, 1995, p.15).

Um sistema autopoiético é um sistema porque seus componentes se manifestam de modo processual. É um sistema fechado porque existe uma circularidade necessária e suficiente de seus componentes para que toda e qualquer operacionalização com vistas à manutenção do próprio sistema se realize. Seu limite, ou suas bordas, diferenciam-se do meio ambiente em que está acoplado. É autopoiético porque "produz e reproduz a si próprio de forma semântica, ou seja, mesmo sendo um sistema operacionalmente fechado, responde às transformações do meio ambiente em que está acoplado, a partir de seus próprios componentes operacionais, com vistas à sua permanência como sistema" (RODRIGUES Jr., 2000, p.263). Aqui ocorre uma inovação com relação à concepção de sistema aberto anteriormente dominante nas abordagens sistêmicas. Para Maturana e Varela (1979) os sistemas autopoiéticos são sistemas auto-referenciados, fechados. A palavra autopoiese (auto = por si só; poiesis = produção) quer dizer produção por si, e expressa a busca, desses autores, de um termo que fosse mais adequado que os até então circulantes, tais como auto-organização ou feedback, e que não incluíam a dimensão semântica, interpretativa (RODRIGUES Jr., 2000).

Para essa abordagem, os sistemas vivos buscam manter a identidade pela subordinação de todas as mudanças através do envolvimento em padrões circulares de interação, onde a mudança em um elemento do sistema é acoplada a mudanças em outro lugar, estabelecendo-se padrões contínuos de interação que são sempre autoreferenciadas. A auto-referência se deve ao fato de que um sistema não pode entrar em interações que não sejam especificadas no padrão de relações que define sua organização. Assim, a interação de um sistema com 
seu ambiente é um reflexo e parte de sua própria organização, facilitando sua autoprodução, já que o ambiente é realmente uma parte de si mesmo. ${ }^{1}$

Como já visto anteriormente, a linguagem ocupa um papel central nas formulações de Maturana e Varela (1986). Segundo esses autores o encontro de um sistema vivo com seu ambiente e com outros seres vivos é de acoplamento estrutural, sendo que o observador o reconhece através de certos fatos (condutas). No entanto, a partir do determinismo e do acoplamento estrutural, a conduta é a descrição feita pelo observador sendo, portanto, uma criação do cérebro. Ao aplicar essas formulações para compreender a comunicação entre os seres humanos, os autores defendem que esta só ocorre por acoplamento estrutural recorrente no decorrer da ontogenia, mantendo a individualidade dos participantes - "cada pessoa diz o que diz e ouve o que ouve, de acordo com a própria determinação estrutural" (MATURANA e VARELA, 1986, p.120). Ou seja, o cérebro cria imagens da realidade como expressões ou descrições de sua própria organização, e interage com essas imagens, modificando-as com base na experiência real. Em organizações sociais, a consequiência é que os membros atuam, e o que se reconhece como organização é um produto de seus pensamentos e ações. "Quando se fala sobre a atuação de uma organização, ou sobre a sustentação de sua identidade, seria mais correto fazê-lo em termos das pessoas-chave envolvidas" (MORGAN, 1996, p.414).

Desde que foi formulada, na década de 1960, a teoria da autopoiese se disseminou de um modo extraordinário, invadindo inúmeros campos de conhecimento. Tem sido utilizada como referência para abordar temas tão diversos quanto a natureza da realidade familiar em processos de psicoterapia, a ontologia da lei, a autoconstituição de sistemas sociais, as bases das ciências cognitivas da vida e de sistemas artificiais (MINGERS, 1995). Para tanto, tem sido descrita como um sistema explicativo amplo e completo, sendo mais um paradigma teórico que uma teoria unificada (KING, 1993).

Segundo Zeleny (1985, p.394), também na aplicação da abordagem da autopoiese a sistemas sociais, existe uma ênfase nos papéis como limitadores da variabilidade. Através da estrutura de papéis, novas pessoas (que poderiam insuflar vida nova), ao ocupá-los, recriam o potencial organizador genético do sistema. Assim, um sistema social de autopoiese pode ser definido como uma "unidade que se realiza por intermédio de uma organização fechada de processos de produção", de modo que "a mesma organização ou os mesmos processos são gerados pela ação de seus próprios componentes", e uma "fronteira topológica emerge como resultado dos mesmos processos constituintes".

Nas ciências sociais a influência mais marcante da abordagem da autopoiese se encontra na obra de Niklas Luhmann, pensador alemão que se propõe a romper com a tradição da sua área de conhecimento. Luhman (1998) critica Parsons pela adoção do modelo de sistema aberto, defendendo que o sistema deve ser diferenciado do seu entorno levando em consideração os processos auto-referenciados (fechamento operacional). Os organismos vivos manejam o sistema por autopoiese auto-organizada de maneira mais complexa que os sistemas mecânicos, conseguindo diminuir, com êxito, a complexidade do entorno. A especificidade do sistema social consiste em que se auto-regula auto-referencialmente, graças à produção de uma estratégia específica de sentido. Cada subsistema também se regula autopoieticamente.

Aplicando-se a teoria de Luhmann (1998) à análise do subsistema econômico, por exemplo, verifica-se que esse tem um código binário sobre o qual se organiza: pagar e não pagar (ter dinheiro/não ter dinheiro), que é o que permite constituir o sentido dos momentos do subsistema. O programa do subsistema se encontra explicitado nos preços que são os que auto-regulam os momentos de pagamento e as expectativas econômicas em geral. O subsistema auto-referente, com base no referido código e programa, comunica-se internamento por meio do dinheiro. Esse é a mediação universal de comunicação no subsistema fechado da economia. Como existe escassez de mercadorias e dinheiro, surgem dois mecanismos: o mercado e a competição. O mercado (em seus diversos níveis) se auto-regula auto-referentemente graças aos preços. A competição no mercado não é um momento discursivo ou autoconsciente, mas, como evita toda interação direta (de possíveis sujeitos) é um mecanismo autopoiético. O subsistema econômico (como todo o sistema) não depende de outros subsistemas (como o político, o social ou o religioso), que são mutuamente autônomos. "Trata-se, exatamente, de uma

\footnotetext{
${ }^{1}$ A idéia de auto-eco-organização, como em Morin (1995).
} 
concepção formalista da economia exclusivamente capitalista, auto-referente, onde as necessidades da vida e do sujeito humano permanecem restritas a mero 'entorno' (isto é, fora de uma consideração sistêmica)" (DUSSEL, 2002, p.256).

"O sistema social, sendo auto-referencial, permite contingência, abertura e interpenetração, mas nunca irrupção do sujeito, do Outro - do sistema psíquico como autônomo; isto é, como uma auto-referência irrespectiva ao próprio sistema social a partir de sua própria dignidade reconhecida a partir da postulação de sua autoconsciência auto-responsável - e tampouco, por isso, se vê claro por que um sistema chega a seu termo e, diacronicamente, como se origina. O que importa a Luhmann é mostrar o modo como o sistema social permanece, respondendo diante de um entorno de suma complexidade. A irrupção da alteridade do Outro criticamente no sistema social, a extinção e originalidade destes sistemas são momentos hetero-referentes que Luhmann evita apresentar claramente. (...) O horizonte luhmanniano continua sendo uma compreensão do sistema social sem sujeitos, dentro de uma paradigma da consciência e a partir da razão instrumental. (...) Luhmann, em nossa visão, se mostra melhor do que nunca nesse texto: A teoria econômica se vê obrigada (de outra maneira não seria útil) a manter sangue-frio diante da diferença rico/pobre. As almas simples tentam fazer oposição ao anterior recorrendo à ética" (DUSSEL, 2002, p.159-260).

Ípola (2001) critica Luhmann por dizer, sob o conceito de acoplamento estrutural, coisas que já vêm sendo ditas há muito tempo, especialmente na sua afirmação de que a historização de um fato social seria uma forma de desvalorizá-lo, de desqualificá-lo como objeto de investigação. Além disso, Ípola (2001) concorda com a abordagem da citação anterior, apontando que a crítica e a recusa ao humanismo, feita por Luhmann, implica em afirmar que o ser humano não é o fundamento nem o centro do processo sóciohistórico.

\section{Teoria da complexidade}

A teoria da complexidade se apresenta como um movimento transdisciplinar que tentaria restabelecer a unidade no estudo da natureza e dos seres humanos, que se teria perdido com a divisão compartimentada decorrente do cartesianismo. Suas origens estão nas abordagens anteriormente revisadas - sistemas, cibernética, autopoiese, mais as contribuições da física, em especial as teorias do caos e de sistemas dinâmicos.

A teoria do caos é um desenvolvimento específico no estudo dos sistemas dinâmicos e que se segue às revoluções teóricas da relatividade e da mecânica quântica. Insere-se na física de partículas, da qual derivam teorias sobre as forças fundamentais da natureza e sobre a origem do universo. Constitui-se em uma ciência da natureza global dos sistemas, provendo argumentos para a pretensão de grande teoria unificada/unificadora que está presente na teoria da complexidade. A teoria do caos se desenvolve com maior ímpeto na década de 1970, especialmente na Universidade de Santa Fé, onde se aprofunda o estudo dos sistemas adaptativos complexos. Esses seriam sistemas formados por unidades simples interligadas entre si, de forma que o comportamento de uma influenciasse o da outra. A complexidade do todo vai decorrer do entrelaçamento de influências mútuas, à proporção que o sistema evolui. Por se manterem em uma situação entre ordem e desordem, esses sistemas só podem ser analisados por meio de simulações computacionais. Dentre suas propriedades estão a nãolinearidade, os fluxos constantes, a diversidade e a estrutura hierárquica. Os estudos de Santa Fé aplicam a teoria do caos, entre outros, na análise das cidades, de aspectos da economia e a ecossistemas (ALEKSANDROWICZ, 2002).

Outro braço da teoria da complexidade reside nas formulações de Ilya Prigogine, segundo as quais:

- nos limites do caos, níveis identificados de energia importada (o que Schröedinger chamava de neguentropia) fazem com que estruturas dissipativas emerjam de comportamentos estocásticos de agregados de microestados;

- as estruturas dissipativas, enquanto existirem, mostram comportamentos previsíveis, ainda que nãocompatíveis com a explicação newtoniana; 
- explicações científicas mais aplicáveis à região em que ocorrem esses fenômenos diferem essencialmente do tipo de complexidade que a ciência newtoniana, o caos determinístico e o mecanicismo estatístico tentam resolver (PRIGOGINE e STENGERS, 1991).

Tarride (1998, p.68) faz uma interessante revisão sobre complexidade e sistemas, recorrendo a Herbert Simon para caracterizar a complexidade dos sistemas.

"Sistemas com muitos componentes podem ser considerados complexos, se comparados aos que têm poucos. A cardinalidade de um conjunto, então, pode ser considerada medida de complexidade. Sistemas caracterizados por muita interdependência de componentes são considerados, geralmente, mais complexos do que os com pouca ou nenhuma. Sistemas 'inenarráveis' (não-demonstráveis ou nãocalculáveis formalmente) podem ser considerados complexos, se comparados aos deterministas. A complexidade dos sistemas pode ser medida pelo conteúdo da informação. (...) Por esse critério, os sistemas com muitos componentes idênticos são menos complexos do que os de tamanho comparável, onde os componentes são muito diferentes."

Continuando em sua revisão, Tarride (1998, p.68) afirma que, ao se considerar a complexidade como propriedade avaliável dos sistemas, seria possível estabelecer modelos para quantificá-la. No entanto, essa vertente teria conduzido a uma mensuração mais do que à compreensão do nível de complexidade de um sistema observado. "Esta constatação conduziu a pesquisa epistemológica contemporânea a renovar os modos de representação da complexidade, a partir da observação de que ela muda de acordo com os códigos utilizados. O postulado de que a complexidade não está na natureza das coisas, mas no modelo construído pelo observador."

"A sistemografia é o procedimento pelo qual se constroem modelos de um fenômeno percebido como complexo, apresentando-o deliberadamente como e por um sistema geral. Entende-se a forma canônica do sistema geral como representação de um fenômeno ativo, percebido como identificável por seus projetos em um ambiente ativo, no qual funciona e se transforma teleologicamente. Os componenteschave desta representação canônica são funções, transformações, finalidade e ambiente. Deve-se deixar claro que a modelagem analítica é objetiva, enquanto a sistêmica é projetiva. Os modelos são construídos mentalmente e representados em um suporte físico. (...) Tipos de modelagem sistêmica: de processos, por níveis teleológicos, da organização, do sistema de tratamento da informação, do sistemaorganização (operação, informação, decisão), inforgético (a organização entendida como energia e informação)" (TARRIDE, 1998, p.71).

Uma outra abordagem da complexidade, de caráter humanista, é encontrada em Morin (1999, p.261), que defende o caráter complexo das relações todo/partes, uno/diverso.

"O todo é mais que a soma das partes (princípio bem explícito e, aliás, intuitivamente reconhecido em todos os níveis macroscópicos), visto que em seu nível surgem não só uma macrounidade, mas também emergências, que são qualidades/propriedades novas. O todo é menos do que a soma das partes (porque elas, sob o efeito das coações resultantes da organização do todo, perdem ou vêem inibirem-se algumas das suas qualidades ou propriedades). O todo é mais do que o todo, porque o todo enquanto todo retroage sobre as partes, que, por sua vez, retroagem sobre o todo (por outras palavras, o todo é mais do que uma realidade global, é um dinamismo organizacional)."

Nesse sentido, a explicação deve procurar compreender o processo cujos produtos ou efeitos finais geraram seu próprio recomeço, processo que é recorrente.

No centro das formulações de Morin (1999, p.267) se encontra um "conceito de caráter paradigmático superior" - o de organização.

"A organização cria ordem (criando o seu próprio determinismo sistêmico), mas também desordem: por um lado, o determinismo sistêmico pode ser flexível, comportar suas zonas de aleatoriedade, de jogo, de liberdades; por outro, o trabalho organizador, como já dissemos, produz desordem (aumento de entropia). 
Nas organizações, a presença e a produção permanente da desordem (degradação, degenerescência) são inseparáveis da própria organização. O paradigma da organização comporta, portanto, nesse plano, igualmente uma reforma do pensamento; doravante, a explicação já não deve expulsar a desordem, já não deve ocultar a organização, mas deve conceber sempre a complexidade da relação organização

desordem $\quad$ ordem."

A organização é, também e simultaneamente, transformação e formação. A transformação é vista como o modo pelo qual as partes de um todo perdem qualidades e adquirem outras novas. A transformação da diversidade desordenada em diversidade organizada é, ao mesmo tempo, transformação da desordem em ordem. A relação ordem/organização é circular. A organização produz ordem que, por sua vez, mantém a organização que a produziu; a ordem transforma a improbabilidade da organização em probabilidade local, em proteção da originalidade do sistema, em resistência contra as desordens do interior (degradação) e do exterior (riscos, agressões) (MORIN, 1999).

Desenvolve-se, a partir de autores vinculados à teoria da complexidade, a abordagem da "scienza nuova", que emparelha a importância de leis e de eventos, com a ambição de edificar uma ciência geral.

"O que quisemos encontrar foi o lugar charneira para as pesquisas fundamentais, foi um conjunto teórico, metodológico e epistemológico, ao mesmo tempo coerente e aberto. Julgamo-lo muito mais coerente que todas as outras teorias que se estendem sobre um domínio bastante vasto, mas que estão reduzidas a repetir incansavelmente as suas generalizações. (...) Colocamos, simultaneamente, a possibilidade e a necessidade de unidade da ciência. Uma tal unidade é, evidentemente, impossível e incompreensível no quadro atual onde miríades de dados se acumulam nos alvéolos disciplinares cada vez mais estreitos e fechados" (MORIN, 1995, p.73).

A teoria da complexidade tem se tornado, no período recente, uma nova moda na administração, através do "circuito cultural do capitalismo" (THRIFT, 1999, p.42) que vincula a produção de conhecimento (academia, consultores e gurus) a sua distribuição (publicações científicas, mídia, seminários) para audiências compostas por gerentes privados (principalmente) e públicos. Esse mesmo autor analisa os motivos pelos quais existe tanta receptividade às metáforas da complexidade:

- os administradores têm, há muitas décadas, pensado em termos de sistemas;

- a familiaridade com tecnologias de informação;

- a necessidade, do circuito cultural do capitalismo, de um fluxo constante de idéias e metáforas, como condição para sua própria existência;

- a produção da teoria da complexidade está conectada com o mundo empresarial - por exemplo, o Instituto Santa Fé, talvez o maior "propagandista" da teoria da complexidade, tem uma intensa conexão com Citicorp no desenvolvimento de aplicações da teoria aos mercados financeiros.

Um dos braços desse instituto, o Santa Fe Center for Emergent Strategies, se propõe a apoiar as empresas em seu maior desafio, o de criar ambientes organizacionais onde estratégias adaptativas possam emergir.

"Desenvolvemos modos para integrar e aplicar lições da ciência da complexidade, de abordagens cognitivas e da administração, para ajudar as empresas a permitirem que a estratégia se torne um processo emergente, uma parte do que cada uma está fazendo, mudando quando as circunstâncias mudem. Nossa meta é ajudar as empresas no desenvolvimento de estratégias para o crescimento corporativo e para que essas estratégias funcionem. Fazemos isso focando em processos estratégicos, indicando como as empresas inovam e competem como sistemas complexos adaptativos" (ABELL, 2003, p.1). 
Tasaka (1999) considera que o "paradigma" da complexidade reconceitua a administração do século XXI. Esse autor sintetiza essa mudança, e sua decorrente aplicação na gestão, através de algumas máximas:

- não analise, intua o todo;

- não planeje ou gerencie, estimule a auto-organização;

- gere informações coerentes, não informação compartilhada;

- a força de uma organização não está no coletivo, mas na habilidade individual de produzir coerência;

- a co-evolução não se dá nem de cima para baixo, nem de baixo para cima - é uma estratégia de integração horizontal e vertical;

- as regras estão sujeitas a mudança;

- não prediga o futuro, crie o futuro.

Goodwin (1997, p.117) sintetiza os conceitos da teoria da complexidade que podem ter utilidade na administração de empresas:

"Corporações empresariais têm estado entre as primeiras a ver a relevância potencial dessas idéias para a estrutura gerencial e para a mudança organizacional criativa. (...) As sugestões da teoria da complexidade para a prática empresarial são o achatamento e a hierarquia gerencial, a distribuição de controle através do sistema com redes fluídas de interação entre as partes, e a necessidade de períodos de caos para a emergência de uma nova e adequada ordem. O movimento na direção de um dinamismo espontâneo e anárquico é, claramente, ameaçador para os gerentes, mas parece ser o caminho para a criatividade e a diversificação. (...) O que ele permite é a expressão inovadora, que tem valor intrínseco para os membros da empresa, assim como oferece a melhor oportunidade para a persistência da organização em um mundo corporativo em constante mudança . Todos os participantes nesse setor da organização social podem vivenciar uma elevação na qualidade de vida, já que têm mais liberdade, mais oportunidades para a ação criativa e interações mais ricas - bom para eles e bom para a organização."

Como sintetiza Zohar (1997, p.9), a aceitação do pluralismo, da diversidade, da ambigüidade e do paradoxo, da complexidade em vez da simplicidade, pode "nos ajudar a repensar a estrutura e a liderança nas organizações". Até mesmo o "insuspeito" Edgar Morin (1995, p.124-136) escreve sobre a aplicação da teoria da complexidade nas empresas.

"A empresa situa-se num mercado. Produz objetos ou serviços, coisas que se lhe tornam exteriores e entram no universo do consumo. Ao produzir coisas e serviços a empresa, ao mesmo tempo, autoproduz-se. Limitar-se a uma visão hetero-produtora da empresa seria insuficiente, porque ao produzir coisas e serviços, a empresa, ao mesmo tempo, se autoproduz. Isso quer dizer que produz todos os elementos necessários à sua própria sobrevivência e à sua própria organização. Ao organizar a produção de objetos e de serviços, se auto-organiza, automantém, se necessário auto-repara-se e, se as coisas vão bem, autodesenvolve-se ao desenvolver a sua produção. Assim, ao produzir produtos independentes do produtor, desenvolve-se um processo em que o produtor se produz ele mesmo. Por um lado, a sua autoprodução é necessária à produção de objetos, por outro, a autoprodução dos objetos é necessária à sua própria autoprodução. A complexidade aparece nesse enunciado: quem produz as coisas ao mesmo tempo autoproduz-se, o próprio produtor é o seu próprio produto. (...) Uma empresa auto-organiza-se no seu mercado: o mercado, um fenômeno ao mesmo tempo ordenado, organizado e aleatório. Aleatório porque não há certeza absoluta sobre as hipóteses e as possibilidades de vender os produtos e os serviços, mesmo se houver possibilidades, probabilidades, plausibilidades. O mercado é uma mistura de ordem e desordem. (...) A ordem é tudo o que é repetição, constância, invariância, tudo o que pode ser colocado sob a égide de uma relação altamente provável, enquadrada sob a dependência de uma lei. A desordem é tudo o que é irregularidade, desvio em relação a uma estrutura dada, aleatório, imprevisibilidade. (...) As organizações têm necessidade de ordem e necessidade de 
desordem. Num universo onde os sistemas sofrem o aumento da desordem e tendem a desintegrar-se, a sua organização permite reprimir, captar e utilizar a ordem. (...) Na empresa, o vício da concepção taylorista do trabalho foi considerar o homem unicamente como uma máquina física. Num segundo tempo, percebeu-se que há também um homem biológico; adaptou-se o homem biológico ao seu trabalho, e as condições de trabalho a esse homem. Depois, quando se verificou que existe também um homem psicológico, frustrado pelas tarefas parcelares, inventou-se o enriquecimento das tarefas. A evolução do trabalho ilustra a passagem da unidimensionalidade para a multidimensionalidade. Estamos apenas no início desse processo. (...) a vontade de impor, no interior de uma empresa uma ordem inexorável é não eficiente. (...) É preciso deixar uma parte da iniciativa a cada escalão e a cada indivíduo. Coloca-se o problema histórico global: como integrar nas empresas as liberdades e as desordens que podem trazer a adaptatividade e a inventividade, mas que podem igualmente trazer a decomposição e a morte. (...) Pode-se dizer, grosseiramente, que quanto mais uma organização é complexa, mais tolera a desordem. Isso dá-lhe uma vitalidade porque os indivíduos estão aptos a tomar iniciativas para regular este ou aquele problema sem ter de passar pela hierarquia central. É uma maneira mais inteligente de responder a certos desafios do mundo exterior. Mas um excesso de complexidade é em definitivo desestruturante. No limite, uma organização que só tivesse liberdade, e muito pouca ordem, desintegrar-se-ia a menos que houvesse como complemento dessa liberdade uma solidariedade profunda entre seus membros. A solidariedade vivida é a única que permite o aumento da complexidade. Finalmente, as redes informais, as resistências colaboradoras, as autonomias, as desordens são ingredientes necessários à vitalidade das empresas."

Novo paradigma! As referências transcritas ao longo desse item parecem rearranjos retóricos de afirmações que circulam, há décadas, na tradição do pensamento e da prática da administração!

\section{Considerações finais}

"A teoria de modelos, integrante da teoria dos sistemas, naturaliza a razão técnica condicionada historicamente, otimiza o atual como sendo o desejável, projeta no futuro a lógica da industrialização automatizada sob o capitalismo monopolista; tão transitória quanto o fora a lógica da industrialização mecanizada, constitui-se na mais sofisticada representação ideológica produzida pela pequena burguesia intelectual: a ideologia do fim das ideologias por quem não possui ideologia alguma. Em outras palavras, cultiva a neutralidade científica como ethos ideológico da Ciência, num universo administrado burocraticamente pelos financiamentos das grandes foundations com os white-collar às suas ordens."

Maurício Tragtenberg

A consideração dessas quatro abordagens sistêmicas permite que se perceba a relação entre as mesmas, como sendo a de uma evolução. Não é por acaso que alguns autores se referem à teoria da complexidade como neosistemismo. Continua a naturalização dos fenômenos, o que remove qualquer possibilidade de construção intencional por parte dos sujeitos que, aliás, estão ausentes como seres criativos e dotados de desejos. Além disso, continua presente o esforço de simplificar (modelando) para apreender a complexidade da realidade social. Outro aspecto comum e questionável é o de transpor conceitos das ciências naturais para compreender a vida em sociedade, eliminando-se, nessa perspectiva, a possibilidade de considerar como julgamentos morais, intencionalidades, razão substantiva, interferem na construção da realidade. Aliás, não existindo a possibilidade do exercício da vontade, tais temas não se colocam como pertinentes.

Essa transposição entre campos de conhecimento se efetiva através do uso de metáforas e da sua capacidade de mobilizar emoções e memórias. De acordo com Thrift (1999), a teoria da complexidade é uma tentativa de substituir um conjunto de metáforas (relacionado à biologia evolucionista de Darwin e à física newtoniana) por outro. $\mathrm{O}$ fato é que seus elementos-chave se moveram rapidamente para outras disciplinas e parecem estar produzindo algumas reconfigurações nas mesmas. Um dos problemas está em que, ao chegar em outros campos, como é o caso da administração, realiza uma apropriação simplista desses elementos, tomando-os não 
mais como metáforas, mas como modelos, ignorando o problema da verdade metafórica. ${ }^{2}$ Gutsatz (apud SERVA, 1992) alerta para a utilização do que denomina conceitos camaleões, bem como para os riscos dessa circulação sem a devida consideração das dificuldades epistemológicas decorrentes do contexto próprio de cada campo de conhecimento.

Souza (2003, p.25) - partindo de uma defesa das potencialidades do paradigma funcionalista sistêmico que se constitui a partir de sociólogos funcionalistas clássicos, como Spencer e Durkheim - afirma que essa abordagem "útil e promissora" corre o risco de se empobrecer, de regredir no reconhecimento da singularidade dos fenômenos sociais e das forças que determinam sua dinâmica, ao adotar conceitos inspirados nas teorias de sistemas e da complexidade. "Sem dispor de uma teoria geral de sistemas que proclamasse as leis dos sistemas naturais como leis gerais, os funcionalistas clássicos olhavam primeiro para os sistemas sociais, e identificavam neles algumas similaridades com sistemas naturais. Após a influência da teoria geral de sistemas, porém, o 'novo funcionalismo' olhava para os sistemas sociais já com a visão viesada pelas leis e regras dos sistemas naturais que esta professava."

"(...) Por que razão deveríamos crer que as leis que regem os sistemas naturais servem para os sistemas sociais? Admitir que essa transposição de conceitos é possível e adequada não implica ver os sistemas sociais como casos específicos de sistemas naturais? Não implica admitir um status de naturalidade a qualquer tipo de organização social? Não implica dissimular a história, destituir o livre arbítrio, a vontade, a intencionalidade e a razão que habita o espírito humano (e não habita as células, os átomos, os planetas ou qualquer outra entidade componente de sistemas naturais)? Não implica (...) em uma opção política pela conservação, seja de qualquer ordem dada (mas uma conservação não baseada em valores, mas em uma inexorável naturalidade da ordem geral)?" (SOUZA, 2003, p.26)

Também preocupado com a capacidade que a teoria da complexidade teria para abordar a complexidade da realidade social Stewart (2001) defende a tese de que a realidade social é por demais complexa para ser explicada pela teoria da complexidade. Ao desenvolver seu argumento Stewart (2001, p.4) critica a retórica freqüentemente associada à idéia de novo paradigma - de que a complexidade pode se constituir em uma metateoria. "O uso da teoria da complexidade como um horizonte paradigmático tem levado a um reducionismo nos estudos sociais, sendo que esse reducionismo é associado à falta de conhecimento sobre o campo. (...) A teoria da complexidade tem se desenvolvido principalmente dentro de campos específicos das ciências naturais." $\mathrm{O}$ autor defende que sem recorrer às especificidades de cada campo social relevante, e sem o engajamento nos debates que concernem a cada campo, o teórico fica em uma posição fraca para fazer afirmações.

Stewart também critica a influência da modelagem matemática, presente na teoria da complexidade, afirmando que os contextos sociais tem históricas físicas, ambientais e humanas particulares, que produzem um único conjunto de condições em cada contexto, sem contar com as condições criadas pelas pessoas nas suas tentativas de atuar reflexivamente sobre os aspectos do contexto. Outro aspecto criticado por esse autor se refere à sistematicidade social, reconhecida a partir do funcionalismo de Parsons e, mais recentemente, pelo trabalho de Luhmann.

"Estas concepções são altamente contestadas. Ainda que o funcionalismo parsoniano usufrua algum apoio, como no caso do trabalho de Luhmann e também entre aqueles aliados ao neofuncionalismo, a crítica à idéia de um sistema social coerente é muito forte. Giddens, por exemplo, utiliza o termo sistema social de um modo mais disperso: algumas sociedades podem ser mais sistemáticas que outras; existem sistemas intersociais; e, além disso, precisamos deixar as imagens de sistemas biológicos e físicos de lado. Bourdieu diz que sua noção de um campo exclui o organicismo e o funcionalismo: os produtos de um dado campo podem ser sistemáticos sem serem produto de um sistema, e especialmente se um sistema caracterizado por funções comuns, coesão interna, e auto-regulação; rejeitando vários postulados da teoria de sistemas. Lyotard acredita que a idéia de uma sociedade como

\footnotetext{
${ }^{2}$ Como se encontra apresentado no início desse texto, a partir das formulações de Ricouer (2000).
} 
uma totalidade unificada é um caso do que Horkheimer chamou de "paranóia da razão"” (STEWART, 2001, p.6).

Outro aspecto da teoria da complexidade se refere à sua pobre relação com tradições da filosofia socialmente relevantes, como a fenomenologia e a hermenêucia, bem como com a psicanálise.

"Quando as abordagens da complexidade entram nos debates sobre o social, se aliam a uma variedade de posições culturais (discurso new wage, estratégia gerencial), posições filosóficas (realismo, marxismo, antipositivismo, pós-estruturalismo), teorias sociológicas (teorias de sistemas, abordagens evolucionistas), tradições religiosas (primariamente orientais e tradições míticas), e posições políticas (democracia, ambientalismo, machiavelismo). Ao mesmo tempo, interesses dentro desses campos têm levado à incorporação de aspectos das novas teorias como ferramentas a serviço de suas próprias estratégias. Entretanto, expoentes da teoria da complexidade têm se identificado, de modo predominante, com um grupo bastante estreito de abordagens filosóficas. Agrupando-as se chega a duas tradições filosóficas tradicionalmente antagônicas: instrumentalismo e naturalismo iluministas. (...) No lado instrumentalista a teoria da complexidade é herdeira da matemática e da biologia, sendo as novas idéias utilizadas, p. ex., para orientar práticas gerenciais. (...) Além disso, a teoria da complexidade possui conexões com uma tradição diferente do iluminismo - a do naturalismo."

Assumindo que as abordagens revisadas nesse ensaio não se diferenciam no essencial, apenas ampliando aspectos a serem considerados, acredita-se que todas as críticas feitas ao referencial sistêmico se aplicam à vertente neo-sistêmica da auto-organização e da complexidade.

O ponto de partida da teoria sistêmica está na premissa de que a natureza da realidade social é um conjunto de fenômenos materiais ou de idéias, crenças e hábitos "externos" ao comportamento dos indivíduos. Assim, as ações humanas e as relações sociais são "fatos" de um mundo objetivo e devem ser concebidas como fenômenos reais, como uma "coisa-em-si" que se encontra fora e independente dos indivíduos e de suas consciências. Nesse aspecto, toda teoria sistêmica guarda uma forte coloração durkheimiana - a natureza da sociedade é constituída por uma totalidade mais ou menos organizada de crenças e sentimentos comuns a todos os membros do grupo (ALVES, 1995).

Segundo esse mesmo autor, a análise é sistêmica "por pressupor grandes construtos lógicos que aprioristicamente têm o poder de invocar as experiências reais dos atores sociais através de sistemas de idéias e imagens que enfatizam a padronização dessa experiência" (ALVES, 1995, p.74).

"Toda teoria sistêmica, embora guarde marcantes diferenças entre si, parte de um mesmo princípio, que pode ser resumido nos seguintes itens: a) admite-se a existência de um todo a ser analisado; b) esse todo está composto de unidades que se configuram distintamente entre si; c) as unidades, contudo, estão agregadas a outras, sendo mutuamente interdependentes; d) essa interdependência está regulada por uma morfologia, uma estrutura. Assim, é pela forma em que se relacionam os componentes do sistema, ou seja, pela estrutura do sistema, que se explica um determinado objeto de estudo. São teorias, portanto, que pressupõem uma determinada codificação do sistema e a tarefa principal do pesquisador é decifrá-la" (ALVES, 1995, p.74).

Dillon (2000) analisa a teoria da complexidade a partir da pergunta sobre que forma de vida essa teoria permite que se construa. Na busca por respostas, ele a relaciona com o pós-estruturalismo. Em ambas as teorias se encontra uma anterioridade da "relacionalidade radical", ou seja, nada existe sem estar relacionado a algo e tudo existe - no seu próprio modo de existir - em termos e em virtude de relações. No entanto, essa anterioridade do relacional está, para os pós-estruturalistas, relacionada a uma radicalidade não-relacional, que é o intratável, o imprevisível, o que resiste a ser submetido. Esse não-relacional transita por todas as relações como um movimento perturbador que previne, continuamente, a completa realização ou o fechamento final da relacionalidade. É a centelha que, continuamente, precipita vida nova e significados novos. Essa persistência do não-relacional no relacional sempre confundirá qualquer noção de ordem. Esse não-relacional só pode ser compreendido por referência ao "outro" que, como ensina Levinas (1998, p.13), não é um caso particular, um tipo de alteridade, mas a "exceção original da ordem". De acordo com Dillon (2000) essa diferença tem 
implicações éticas ${ }^{3}$ e, conseqüentemente, origina projetos também diferentes. O retorno a Aristóteles e à diferença entre poiesis e praxis permite compreender a maior disposição para a estratégia entre pensadores da complexidade, bem como seu compromisso com o projeto científico moderno (apesar do esforço para distanciarem-se do modelo newtoniano de ciência). ${ }^{4}$ Também permite compreender a ênfase em códigos e taxonomias como base para compreender a formação e mudança através de novos tipos de causalidade. Nesse processo, a capacidade potencial é uma dimensão do próprio jogo de relações que, desse modo, pode ser visto como um jogo de possibilidades finitas de forças e formas.

A teoria da complexidade tem uma preocupação estratégica com a sua "contínua capacidade de intervir na orquestração do jogo da objetivação e da subjetivação" (DILLON, 2000, p.14). Isso fica evidente na defesa, feita por Morin (1995, p.74), de que essa teoria corresponderia "à possibilidade e à necessidade de unidade da ciência". ${ }^{5}$ Além disso, especialmente em sua apropriação pela administração, pelas ciências sociais e militares, a teoria da complexidade reforça a visão de que o poder, como relacionalidade estrategizante, pressupõe uma vida que gera a operacionalização ordenada do próprio poder.

Retornando à sua pergunta inicial, Dillon (2000, p.22) responde que a vida autorizada pela teoria da complexidade é a que decorre do conhecimento da morfogênese (das estruturas), da inteligência, da sobrevivência, da flexibilidade e, é claro, do ajuste à complexidade. Não é, jamais, a da alteridade, da diferença, da imprevisibilidade, da responsabilidade e da justiça.

Finalmente, para dar conta da complexidade no estudo do mundo social, algumas abordagens têm mais possibilidades de sucesso que a teoria da complexidade. Esse é o caso, entre outras, do uso da narrativa e da interpretação (com abertura teórica e empírica); do cuidado com a pluralidade e com as diferenças; do reconhecimento de que as formações sociais são hiper complexas, ambíguas, extensivas e refletem particularidades (que mesmo a teoria da complexidade não é capaz de descrever ou explicar); da natureza da sociedade e da complexidade social (questões abertas que precisam do aporte de todo o conhecimento das humanidades, mais do que de uma teoria que clama por privilégios frente às demais); da importância da linguagem para construir e narrar o social; do reconhecimento da relevância de discursos particulares e da natureza relacional dos processos sociais; bem como, da relevância da hermenêutica, que desloca qualquer modelo formal e adota elementos propositivos e relacionais, os quais podem ser analisados somente através de interpretações sempre em disputa (STEWART, 2001).

Para encerrar é preciso dizer que os aportes da teoria de sistemas à teoria da complexidade são de grande valia para o desenvolvimento da administração como parte do projeto das ciências sociais funcionais que, segundo Dussel (2002), tem um sentido positivo, de fazer que o que está vigente funcione, opere e se desenvolva. No entanto, para aqueles que gostariam de ver o contexto da vida organizacional e da produção do conhecimento em administração mudando na perspectiva da emancipação dos sujeitos, não resta dúvida que os aportes dessa teoria são de pouca utilidade.

\footnotetext{
${ }^{3}$ Ética é aqui entendida em termos de ethos, de formas de vida que pressupõem e autoriza.

${ }^{4}$ A esse respeito ver Tsoukas e Hatch (2001), que mostram como a pretensa ruptura com o modelo dominante de produzir conhecimento não passa de mera retórica por parte dos autores vinculados à teoria da complexidade. Recorrendo às formulações de Bruner (1998) e à distinção entre os modos de pensamento lógico-científico e narrativo, verifica-se como continua presente, na teoria da complexidade, a busca por condições universais para se chegar ao conhecimento verdadeiro, bem como a já mencionada referência a modelos biológicos e naturais.

${ }^{5} \mathrm{O}$ eterno sonho do sistemismo!
} 


\section{Referências bibliográficas}

ABELL, B. Complexity and business: practical lessons from the natural world. Disponível em: $<$ <ttp://www.santafeassociates.com/html/_complexity_and_business_prac.html>. Acesso em: 14 maio 2003.

ALEKSANDROWICZ, A. M. C. Complexidade e metodologia: um refinado retorno às fronteiras do conhecimento. In: MINAYO, M. C. de S.; DESLANDES, S. F. Caminhos do pensamento: epistemologia e método. Rio de Janeiro: Editora da FIOCRUZ, 2002. p.49-81.

ALVES, P. C. A perspectiva da análise social no campo da saúde: aspectos metodológicos. In: CANESQUI, A. M. (Org.). Dilemas e desafios das ciências sociais em saúde. São Paulo: HUCITEC, 1995. p.63- 82.

BEER, S. Cibernética na administração: uma introdução. São Paulo: IBRASA, 1979.

BLACK, M. Models and metaphors. Itaha: Cornell University Press, 1962.

BOURDIEU, P.; CHAM BOREDON, J.- C.; PASSERON, J.-C. A profissão de sociólogo: preliminares epistemológicas. 3. ed. Petrópolis: Vozes, 1999.

BRUNER, J. Realidade mental, mundos possíveis. Porto Alegre: Artes Médicas, 1998.

CADWALLER, M. L. Análisis cibernético del cambio. In: ETZIONI, A.; ETZIONI, E. Los cambios sociales: fuentes, tipos y consecuencias. MéxiCo: Fondo de Cultura Econõmica, 1968. p.149-153.

CANGUILHEM, G. Ideologia e racionalidade nas ciências da vida. São Paulo: Livraria Martins Fontes, 1977.

. Le tout et la partie dans la pensée biologique. In: BOURDIEU, P.; CHAMBOREDON, J.- C.; PASSERON, J.-C. A profissão de sociólogo: preliminares epistemológicas. 3. ed. Petrópolis: Vozes, 1999. p.167-169.

DEBRUN, M. A idéia de auto-organização. In: DEBRUN, M.; GONZALES, M. E. Q.; PESSOA JR., O. (Orgs.). Auto-organização: estudos interdisciplinares em filosofia, ciências naturais e humanas e artes. Campinas: CLE, 1996.

DILLON, M. Poststructuralism, complexity and poetics. Theory, Culture \& Society, v.17, n.5, p.1-26, 2000.

DUSSEL, E. Ética da libertação: na idade da globalização e da exclusão. 2. ed. Petrópolis: Vozes, 2002.

GOODM AN, N. Languages of art: an approach to a theory of symbols. Indianapolis: Bobbs-Merril Co., 1968.

GOODWIN, B. C. Community, creativity and society. Soundings, n.5, p.111-123, 1997.

INGOLD, T. An anthropologist looks at biology. Man, n.25, p.208-229, 1990.

ÍPOLA, E. de. Metáforas de la política. Santa Fé: Homo Sapiens Ediciones, 2001.

KATZ, D.; KAHN, R. L. Psicologia social das organizações. São Paulo: Atlas, 1975.

KING, M. The truth about autopoiesis. Journal of Law and Society, v.20, n.5, p.218-136, 1993.

LEVINAS, E. Of God who comes to mind. Standford: Standford University Press, 1998.

LUHMANN, L. Sistemas Sociais. Buenos Aires: Anthropos, 1998.

MATURANA, H.; VARELA, F. Autopoiesis and cognition: the realization of the living. London: Reidl, 1979.

. El árbol de conocimiento. Santiago: Universitária, 1986.

. De máquinas y seres vivos - autopoiesis: la organización de lo viviente: Santiago: Universitária, 1995.

MINGERS, J. Self-producing systems: implications and applications of autopoiesis. London: Plenum, 1995.

MORGAN, G. Images of organization. London: Sage, 1996.

MORIN, E. Introdução ao pensamento complexo. 2. ed. Lisboa: Instituto Piaget, 1995.

. Ciência com consciência. 3. ed. Rio de Janeiro: Bertrand Brasil, 1999.

PARSONS, T. Una teoria funcional del cambio. In: ETZIONI, A.; ETZIONI, E. Los cambios sociales: fuentes, tipos y consecuencias. México: Fondo de Cultura Económica, 1968. p.84-96.

. Os componentes dos sistemas sociais. In: CARDOSO, F. H.; IANNI, O. Homem e sociedade: leituras básicas de sociologia geral. São Paulo: Editora Nacional, 1973a. p.56-59.

. 0 conceito de sistema social. In: CARDOSO, Fernando Henrique; IANNI, Octavio. Homem e sociedade: leituras básicas de sociologia geral. São Paulo: Editora Nacional, 1973b. p.47-55.

PRIGOGINE, I.; STENGERS, I. A nova aliança. Brasília: Editora da UnB, 1991.

RICOUER, P. A metáfora viva. São Paulo: Edições Loyola, 2000. 
RODRIGUES J r., L. Autopoiesis e o sistema social de Niklas Luhman: a propósito de alguns conceitos. Sociologias, v.2, n.3, p.254-265, 2000. SERVA, M. 0 paradigma da complexidade e a análise organizacional. Revista de Administração de Empresas, v.32, n.2, p.26- 35 , 1992.

SOUZA, R. S. de 0 funcionalismo sistêmico nas teorias sociais e organizacional: evolução e crítica. Disponível em: <http://read.ea.ufrgs.br/read19/artigo/artigo1.htm>. Acesso em: 30 maio 2003.

STEWART, P. Complexity theories, social theory, and the question of social complexity. Philosophy of the Social Sciences, v.31, n.3, p.323360, 2001.

TARRIDE, M. I. Saúde pública: uma complexidade anunciada. Rio de J aneiro: FIOCRUZ, 1998.

TASAKA, H. Twenty-first-century management and the complexity paradigm. Emergence, v.7, n.4, p.115-123, 1999.

THRIFT, N. The place of complexity. Theory, Culture \& Society, v.16, n.3, p.31-69, 1999.

TRAGTENBERG, M. Burocracia e ideologia. São Paulo: Editora Ática, 1980.

TSOUKAS, H.; HATCH, M. J. Complex thinking, complex practice: the case for a narrative approach to organizational complexity. Human Relations, v.54, n.8, p.979-1013, 2001.

ZELENY, M. Spontaneous social order. International Journal of General Systems, v.11, p.117-131, 1985.

ZOHAR, D. Revewing the corporate brain: using the new science to rethink how we structure and lead organizations. San Francisco: Berret-Koehler, 1997. 